Necdet Karlı

Mehmet Zarifoğlu

Mustafa Ertaş

Sabahattin Saip

Vesile Öztürk

Şebnem Bıçakçı

Cavit Boz

Deniz Selçuki

Atilla Oğuzhanoğlu

Münife Neyal

Aksel Siva

Ceyla İrkeç

Hakan Kaleağası

Tülay Kansu

Yakup Sarica

Nebahat Taşdemir

Nevzat Uzuner

\section{Economic impact of primary headaches in Turkey: a university hospital based study: part II}

Received: 27 January 2006

Accepted in revised form: 27 February 2006

Published online: 15 March 2006

\section{N. Karlı (西) • M. Zarifoğlu}

Department of Neurology,

School of Medicine

University of Uludag

16059 Gorukle, Bursa, Turkey

e-mail: nkarli@uludag.edu.tr

Tel.: +90-224-4428308

Fax: +90-224-4429177

\section{Ertaş}

Istanbul School of Medicine,

University of İstanbul

S. Saip • A. Siva

Cerrahpaşa School of Medicine,

University of İstanbul

\section{V. Öztürk}

School of Medicine,

University of Dokuz Eylül

Ş. Bıçakçı • Y. Sarıca

School of Medicine,

University of Çukurova

C. Boz

School of Medicine,

University of Karadeniz Technic
D. Selçuki

School of Medicine,

University of Celal Bayar

A. Oğuzhanoğlu

School of Medicine,

University of Pamukkale

M. Neyal

School of Medicine,

University of Gaziantep

C. İrkeç

School of Medicine,

University of Gazi

H. Kaleağası

School of Medicine,

University of Mersin

T. Kansu

School of Medicine,

University of Hacettepe

N. Taşdemir

School of Medicine, University of Dicle

N. Uzuner

School of Medicine,

University of Osmangazi

\begin{abstract}
This study was planned to investigate the economic impact of headache on Turkish headache sufferers attending a tertiary care outpatient headache clinic.

A total of 937 headache patients were included in this study and questioned using a questionnaire for the profile of patients and headache, quality of life of patients and economic impact of headache. The median total direct cost was found to be 88.0 USD and the median total cost was 160.7 USD. The drug treatment cost was the highest item followed by the specialist outpatient care cost. The average lost and inefficient work/school days was $1.5(0-45)$ and 8.4 $(0-100)$ days for one year. It was shown that loss of productivity was higher for migraine without aura group when compared with the episodic and chronic tension-type headache groups. The results of this nationwide university hospital based study
\end{abstract}


showed that headache, especially migraine, has considerable economic impact on patients.

Key words Headache - Tensiontype headache $\cdot$ Migraine $\cdot$ Economic impact $\cdot$ Loss of work days

\section{Introduction}

Headache is one of the most common complaints, with a lifetime prevalence of $95 \%$ for women and $90 \%$ for men [1]. Migraine has a 1-year prevalence rate of $10 \%-12 \%$ and a lifetime prevalence rate of $12 \%-18 \%$, which is ageand gender-dependent in community-based studies from different parts of the world [2]. The lifetime prevalence of migraine in Turkey was defined as $8 \%$ in males and $17 \%$ in females in a nationwide epidemiological survey [3]. The prevalence of tension-type headache (TTH) was found to be $31.7 \%$ in this survey [3]. The International Headache Society (IHS) defined the criteria for all headache types, mainly migraine and TTH [4], which is pathophysiologically less understood but more frequent, with a 1-year prevalence rate of $60 \%$, than migraine [5].

Although treatment modalities have improved in recent years, headache, particularly migraine, continues to be one of the major health problems resulting in deterioration in the quality of life (QoL), social life and work capacity of sufferers and is an important economic burden on society [6-8]. Headache sufferers were reported to experience more restriction of their daily activities than patients with depression, osteoarthritis, diabetes or hypertension [9]. Migraine, quadriplegia, psychosis and dementia are accepted to be the most disabling diseases, which cause maximum functional loss in patients' life, by the World Health Organization [10]. In a population survey, it was found that half of migraine and TTH sufferers discontinued normal activities during their attacks and most of them required bed rest, preventing them from going to work or working efficiently [11]. Headache sufferers are mostly at their most productive ages. Migraine has its peak prevalence between 20 and 40 years of age. Such a common disorder in these very productive ages causing more disability and restriction of life than many other severe diseases has an important effect on the patients themselves, on society and the economy as well. A number of studies in West European and North American countries have shown this effect, particularly the economic part [12-15]. In a large epidemiological survey in France, total annual direct healthcare costs were estimated to be 128 per individual with migraine in 1999 and the total annual direct cost of other forms of episodic headache was much lower at 28 per individual [12]. Besides direct cost, indirect costs such as lost productivity have been shown to be an important economical burden on societies [16, 17]. As headache is such a prevalent disorder, even the smallest economic loss per person might have a great impact on the countries' economies. This economic loss means a lot more to a developing country than a developed country. The economic burden of headache has mostly been investigated in Western European or North American countries. This study aimed to investigate the economic burden of headache on the patient and the society in tertiary care headache centres in a developing country.

\section{Patients and methods}

This was a cross-sectional epidemiological survey performed in university hospitals located in the seven main geographical regions of Turkey, between December 2001 and August 2002. All centres started recruitment on different dates according to the convenience of their schedules and the study was terminated on 31 August. Different numbers of patients (30-120) were recruited from headache centres.

All patients with a diagnosis of primary headache according to the International Classification of Headache Disorders I [18] were recruited randomly from outpatient headache clinics and questioned for the profile of patients and headache according to IHS criteria [18], treatment approaches and methods used for diagnosis during the last year, QoL of patients and socioeconomic impact of headache on the patients and society. The study questionnaire was applied to the patients face to face by trained research assistants at outpatient headache clinics. Before administering the questionnaire patients were asked if they had a headache or not. Patients who had a headache were called on a headache-free day in order to form a unique group and prevent the effects of headache on patients' cooperation.

This paper represents the results of the economic impact of primary headaches on the patients and indirectly on the Turkish economy.

The study data were collected using a questionnaire that contains 50 questions. Details were given in the Patients and meth- 
ods section of the first part of this study. Direct costs of headache and cost of loss of productivity were the parameters evaluated for this study.

\section{Statistical methods for economic analysis}

Five types of direct costs were used: primary care physician cost, cost for diagnostic work-up, specialist outpatient care cost, drug treatment and hospital costs. These were added to come up with the total direct cost of headache for each patient. Primary care physician and specialist outpatient care costs were calculated on the basis of physician visits. Annual drug treatment costs were calculated on the basis of monthly average analgesic consumption and if a patient had received a prophylactic treatment then the cost was added. Prophylactic treatment was calculated according to the duration of the treatment and prescribed drug cost. Indirect cost of headache was calculated by the means of the loss of work days and loss of efficiency at work. The total cost of headache to the patient and the society was the sum of direct and indirect costs. The ratio of total cost of headache per patient to Gross National Product per capita estimated from the Turkish State Institute of Statistics (3383 USD) was used to calculate the ratio of costs to average income. The foreign exchange conversion rate of the Ministry of Finance as of 1 March 2004 (1 USD: 1314825 Turkish Lira (TL)) was used to convert expenditure into United States Dollars on which date the drug prices for 2004 were released by the Ministry of Health. The applicable charges for the same date for hospital stay, outpatient visits and diagnostic work-up were retrieved from the price list declared by the Ministry of Finance.

The indirect cost calculations used the current daily minimum wage of 14.08 USD, announced by the government officially twice a year, as the cost of the loss of a work day. Two inefficient days at work were regarded as a day absent from work.

Outcome data were classified according to types of headache and several patient characteristics. Cost analysis excluded one patient without adequate financial data. Patients who suffer from more than one headache type (other than combined headache) were excluded from the cost analysis of the subgroups of headaches that they were suffering from. Those patients have been analysed under the heading of other headaches, which included cluster headache, paroxysmal hemicrania, other infrequent primary headaches and multiple headache diagnosis. Chronic daily headache was used for chronic migraine, 15 or more migraine days in a month.

The differences between different patient subgroups for cost and loss of productivity were analysed using the
Mann-Whitney $U$-test for dichotomous groups while Kruskal-Wallis and Jonckheere-Terpstra tests were used for groups with nominal and ordinal categories, respectively. The level of statistical significance was defined as $p<0.05$ for global comparisons. With the region and headache type variables pairwise comparisons were performed using Bonferroni correction which pushed the $p$ value level of significance down to 0.00341 for multiple comparisons.

The corresponding author's university ethics committee approved the study and all patients gave informed consent prior to their inclusion in the study.

\section{Results}

\section{Patients' profile}

A total of 937 patients $(81.5 \%$ female and $71 \%$ over 30 years of age) were included in the study. One patient was excluded because of inadequate data. The headache profile and QoL of patients were summarised in the first part of this study. The frequency of severe headache was highest in chronic daily (5 attacks/week and 16 attacks/month) and chronic tension-type (5 attacks/week and 14 attacks/month) headache. The number of headache days in a month were 20 days for chronic daily headache, 17 days for chronic TTH and 13 days for combined headache sufferers.

\section{Diagnosis and treatment of headache}

The most common diagnostic tests were blood tests $(53.2 \%)$, plain X-ray $(50.0 \%)$ and cranial CT scan (44.5\%) followed by cranial MR $(21.1 \%)$.

Only $4 \%$ of the patients had been hospitalised for treatment of headache. Over $93 \%$ of the subjects used analgesics when they had headache, while $18 \%$ of all subjects used analgesics regularly and $28 \%$ of all subjects used a prophylactic agent regularly prescribed by a doctor in addition to the analgesics. The most common analgesic used for headache attacks was naproxen sodium $(77.0 \%)$. Naproxen and paracetamol were also the most common analgesics used regularly (26.4\% and $17.4 \%$ respectively) (Table 1$)$. The most common prophylactic agents prescribed were amitriptyline $\mathrm{HCl}(31.0 \%)$ and sertraline (21.0\%).

About one-tenth $(9 \%)$ of the whole study population preferred alternative therapies to relieve headache. These therapies included herbal drugs (33\%), physiotherapy/regular massage (24\%), acupuncture (18\%), seeking help from religious sources $(16 \%)$ and relaxation techniques $(14 \%)$. 


\section{Direct and total costs}

As shown in Table 2, the average total direct cost per patient was found to be 162.0 USD with a median of 88.0 USD (range: 7.6-1748.2). The average total cost (both direct costs and indirect costs) was 242.2 USD with a median of 160.7 USD (range: 7.6-1908.5). The average ratio of total cost per patient to Gross National Product per capita for Turkey, which is 3383 USD for 2003, is $7.2 \%$ with a median of $4.7 \%$ (range: $0.2 \%-56.5 \%$ ). The drug treatment cost was the highest item (mean: 124.4 USD) followed by the specialist outpatient care (mean: 18.1 USD) and diagnostic work-up (mean: 17.6 USD) costs. In Table 3 all costs used to calculate direct and indirect costs are given in detail.

Subgroup analysis showed that the direct costs significantly differed by the type of headache and region of residence. Age group, gender and education level differences were found to be statistically insignificant. Total direct cost per patient was highest at 178.7 USD in the age group of 20-29 years. Migraine with and without aura had the highest average total direct costs per patient, which were 250.5 USD and 225.6 USD respectively. TTH groups (episodic and chronic) had lower costs when compared to both migraine with aura (MA) and migraine without aura (MO). Southeastern Anatolia had higher costs when compared to the other regions (Table 2).

\section{The loss of productivity}

The loss of productivity was studied with the lost and inefficient work or school days in the last year. Loss of work/school days ranged between 0 and 45 while decreased work/school efficiency was reported to range from 0 to 100 days for one year. The loss of work/school days was highest in $\mathrm{MO}, \mathrm{CDH}$ and combined headache (migraine and TTH) groups. It was shown that loss of work/school days was higher for MO when compared with the episodic and chronic TTH groups.

The differences in inefficient work or school days among groups were only statistically significant between the episodic TTH and combined headache groups, the former causing the least and the latter causing the highest number of inefficient work/school days (Table 3).

\section{Discussion}

In the second part of this large university hospital based cross-sectional survey investigating tertiary care headache patients' profile, characteristics of primary headaches and the effects of headaches on QoL, we primarily focused on the economic impact of headache on patients and society.

Although there is a great heterogeneity of costs of work/school days in Turkey, we calculated the indirect costs of headache as loss of productivity and loss of work/school days/year, regarding minimum wage in Turkey, which is approximately 14.08 USD/work day, announced by the government officially twice a year. We calculated the direct cost of headache, which is the sum of subcomponents like primary care physician costs, cost for diagnostic work-up, specialist outpatient care costs, drug treatment costs and hospital costs.

The average total direct cost per patient was found to be 162.0 USD, with a median of 88.0 USD (range: 7.6-1748.2). Von Korff et al. [19] defined the cost of headache in a good-outcome group as 307 USD and in a poor-outcome group as 750 USD per patient per year. When compared to a French study, our total direct cost for migraine is nearly two times higher [12]. In Spain, another Mediterranean country, both direct and indirect

Table 1 The analgesics used by patients for individual headache attacks and on a regular basis, either prescribed by physicians or obtained by patients themselves $(n=936)$

\begin{tabular}{lcc}
\hline Analgesic & Used only for individual headache attacks $(\%)$ & On a regular basis $(\%)$ \\
\hline Naproxen Na & 77.0 & 26.4 \\
Paracetamol & 74.0 & 17.4 \\
Metamizol Na & 35.0 & 15.5 \\
Flurbiprophen & 16.0 & 18.6 \\
Ergotamine & 15.0 & 11.8 \\
Acetyl salicylic acid & 12.0 & 3.7 \\
Diclofenac Na & 12.0 & 6.8 \\
Nimesulid & 11.0 & - \\
Sumatriptan & 7.0 & 3.7 \\
Zolmitriptan & - & 5.6 \\
\hline
\end{tabular}


Table 2 Total direct costs by patient subgroups

\begin{tabular}{|c|c|c|c|c|c|}
\hline & & $n$ & Mean (SD) & Median (range) & Significance \\
\hline All patients & & 936 & $162.0(225.9)$ & $88.0(7.6-1748.2)$ & \\
\hline \multirow[t]{6}{*}{ Age group } & $<20$ & 53 & $101.1(124.9)$ & $31.5 \quad(7.6-566.3)$ & $\begin{array}{l}p=0.42, \text { Jonckheere-Terpstra } \\
\text { test for trend }\end{array}$ \\
\hline & $20-29$ & 247 & $178.7(265.1)$ & $88.0(7.6-1450.1)$ & \\
\hline & $30-39$ & 277 & $164.5(203.4)$ & $95.1(7.6-1219.0)$ & \\
\hline & $40-49$ & 246 & $156.9(206.5)$ & $92.4(7.6-1490.0)$ & \\
\hline & $50-59$ & 93 & $162.3(276.4)$ & $56.8(7.6-1748.2)$ & \\
\hline & $60-64$ & 20 & $146.8(152.2)$ & $100.8 \quad(7.6-647.9)$ & \\
\hline \multirow[t]{2}{*}{ Gender } & Female & 763 & $165.5(227.5)$ & $91.3(7.6-1748.2)$ & $\begin{array}{l}p=0.17, \text { Mann-Whitney } \\
U \text {-test }\end{array}$ \\
\hline & Male & 173 & 146.8 (218.9) & $79.0(7.6-1450.1)$ & \\
\hline \multirow[t]{6}{*}{$\begin{array}{l}\text { Geographical } \\
\text { regions }\end{array}$} & Southern & 129 & $125.6(184.5)$ & $53.2(7.6-1108.3)$ & $\begin{array}{l}p<0.001, \text { Mann-Whitney } \\
U \text { with Bonferroni correction* }\end{array}$ \\
\hline & Southeastern & 124 & $222.6(154.2)$ & $258.8 \quad(7.6-833.7)$ & \\
\hline & Northwestern & 335 & $165.8(250.0)$ & $83.5(7.6-1748.2)$ & \\
\hline & Western & 148 & $140.3(216.6)$ & $73.0(7.6-1207.0)$ & \\
\hline & Central & 130 & $200.9(288.5)$ & $96.2(7.6-1490.0)$ & \\
\hline & Northern & 70 & $77.5(87.5)$ & $44.9 \quad(7.6-373.8)$ & \\
\hline \multirow[t]{3}{*}{ Marital status } & Married & 700 & $163.2(220.3)$ & $91.3(7.6-1748.2)$ & $p=0.28$, Kruskal-Wallis test \\
\hline & Single & 199 & $164.3(251.9)$ & $77.6(7.6-1450.1)$ & \\
\hline & Divorced/widowed & 37 & $128.6(181.6)$ & $53.2 \quad(7.6-911.4)$ & \\
\hline \multirow[t]{5}{*}{ Education } & No formal education & 59 & $200.3(289.4)$ & $125.5(7.6-1748.2)$ & $\begin{array}{l}p=0.53 \text {, Jonckheere-Terpstra } \\
\text { test for trend }\end{array}$ \\
\hline & Primary school & 231 & $143.2(211.9)$ & $71.5(7.6-1232.0)$ & \\
\hline & Secondary school & 107 & $185.6(232.6)$ & $128.3(7.6-1490.0)$ & \\
\hline & High-school & 282 & $164.9(219.7)$ & $96.6(7.6-1224.5)$ & \\
\hline & University & 248 & $158.3(227.0)$ & $84.6(7.6-1450.1)$ & \\
\hline \multirow[t]{7}{*}{ Type of headache } & Episodic tension & 159 & $93.0(115.1)$ & $39.1 \quad(7.6-833.7)$ & $\begin{array}{l}p<0.001, \text { Kruskal-Wallis } \\
\text { test } * *\end{array}$ \\
\hline & Chronic tension & 168 & $104.8(122.3)$ & $53.5 \quad(7.6-833.7)$ & \\
\hline & MA & 72 & $225.6(206.8)$ & $183.3 \quad(7.6-979.1)$ & \\
\hline & MO & 241 & $250.5(290.4)$ & $160.5(7.6-1490.0)$ & \\
\hline & Combined headache & 126 & $197.4(281.4)$ & $109.8(7.6-1219.0)$ & \\
\hline & $\mathrm{CDH}$ & 51 & $120.7(110.7)$ & $105.3 \quad(7.6-566.3)$ & \\
\hline & Other & 119 & $97.8(208.2)$ & $22.8(7.6-1748.2)$ & \\
\hline
\end{tabular}

$S D$, standard deviation; $M A$, migraine with aura; $M O$, migraine without aura; $C D H$, chronic daily headache

$*_{p}<0.001$ for Southeastern $v s$. all other regions with Mann-Whitney $U$-test; $* * p<0.001$ for episodic tension $v s$. MA, episodic tension $v s$. $\mathrm{MO}$, chronic tension $v s$. MA, chronic tension $v s$. MO; $p=0.001$ for MA $v s$. $\mathrm{CDH} ; p=0.002$ for episodic tension $v s$. combined headache with Mann-Whitney $U$-test

total costs were higher [20]. Badia et al. [20] reported that the highest item in direct cost was primary care visits, but it was medication in our study. The relatively lower direct costs of headache in our study might be explained by the cheapness of the costs of diagnostic and treatment tools in Turkey and general lower tendency of Turkish patients to seek medical care. The explanations for the large range of direct costs in this study are the heterogeneity of severity of headache and probably socioeconomic level of the studied population.
This hypothesis was supported by the findings of the significant difference in the direct costs of headache regarding the type of headache and region of residence. Patients with MA and MO were defined to have higher costs compared to TTH. The highest total cost for headache was in the Southeastern region. The education level in this region is the lowest in Turkey. This might have resulted in inappropriate use of medication and healthcare facilities, which might have resulted in higher costs. In the western part of Turkey, total cost is in the 


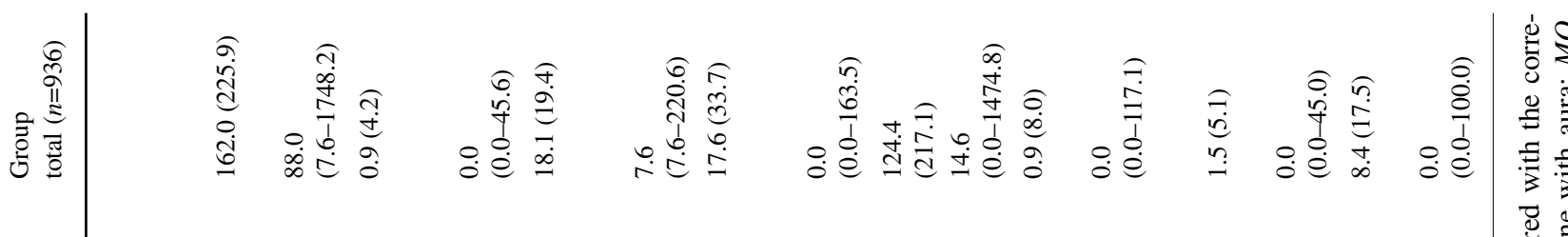

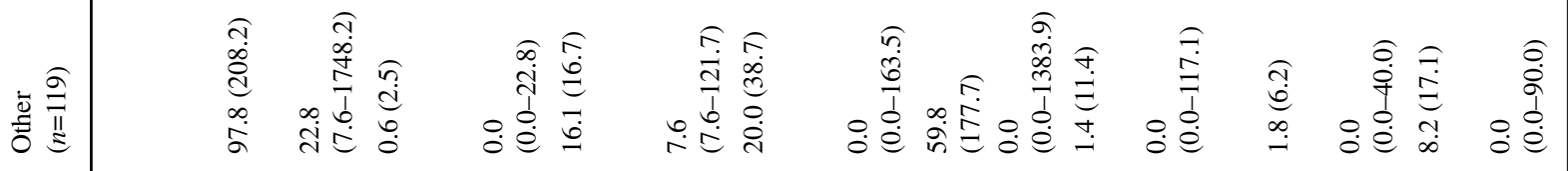

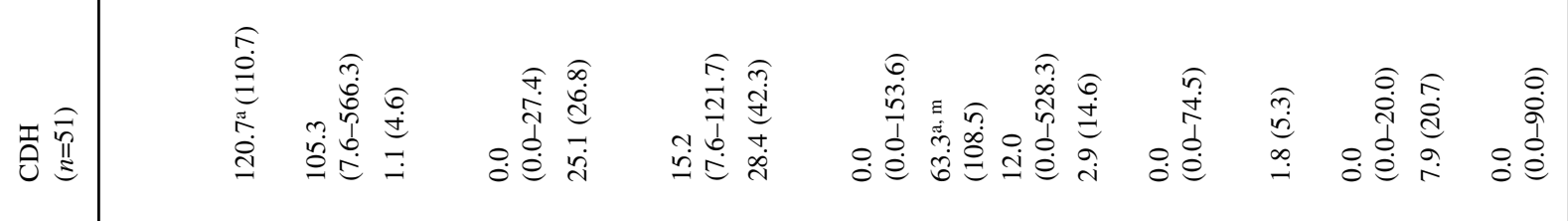

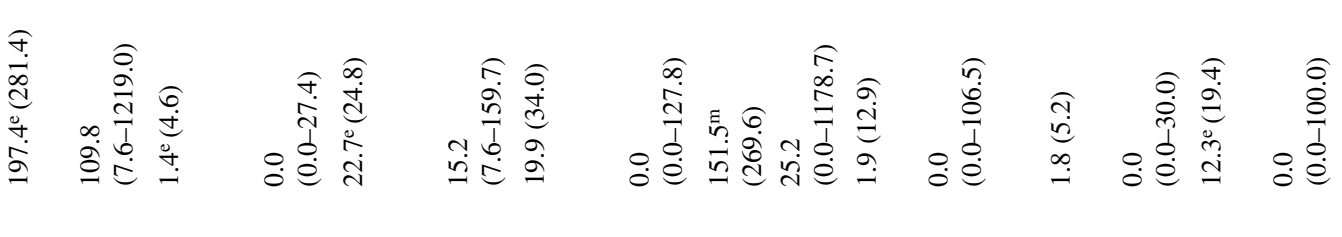

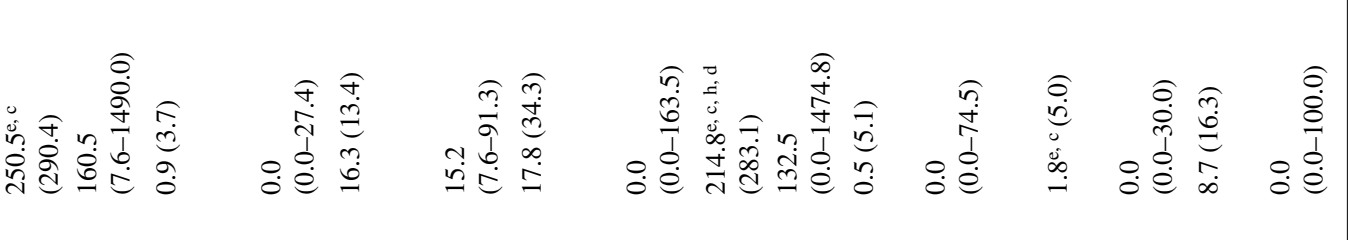

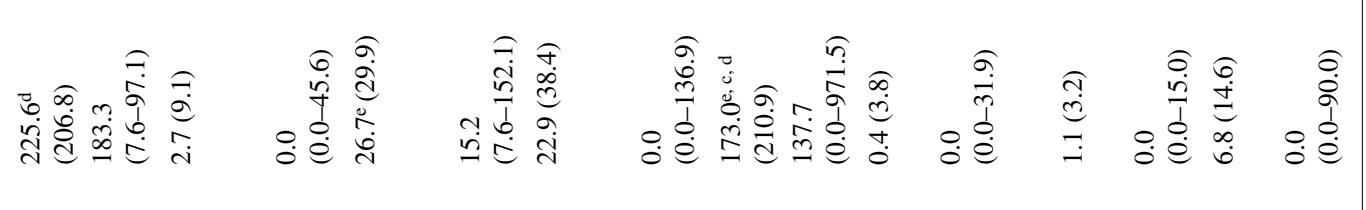

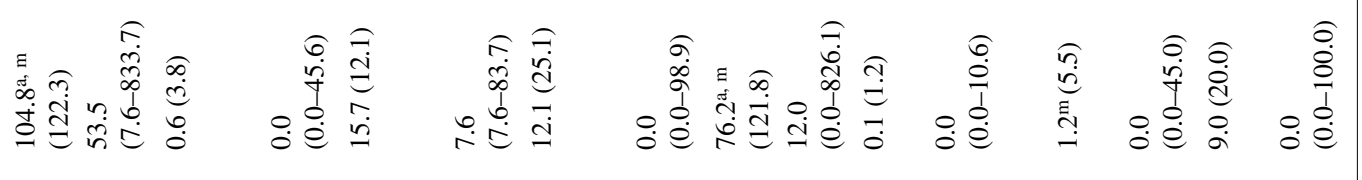

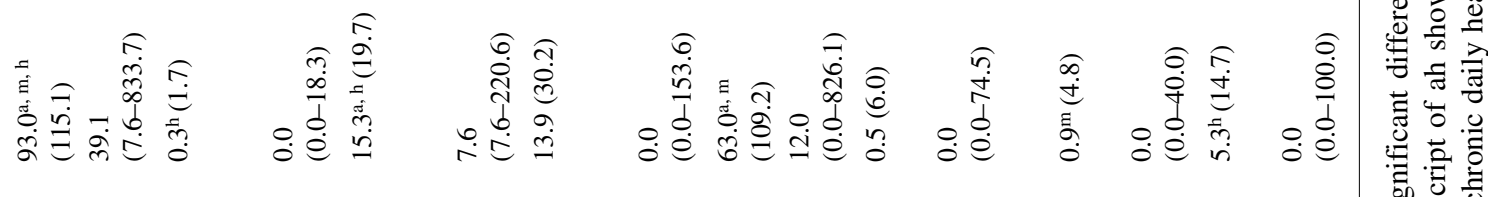

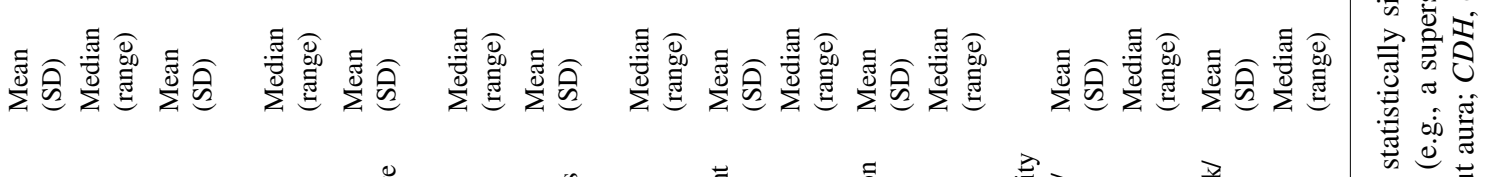


middle range. These regions are the most developed regions of Turkey. Education level is higher than other regions. As seen in the education-total cost relation, education has a decreasing effect on the total cost of headache. Highly educated headache patients might avoid trigger factors and might have received better headache management.

In this study, the drug treatment cost was the highest item (mean: 124.4 USD) followed by the specialist outpatient care (mean: 18.1 USD) and diagnostic work-up (mean: 17.6 USD) costs. This study was conducted in the university hospitals" "tertiary-care" headache outpatient clinics. In Turkey, most of the patients of the university hospitals are covered by social security institutions of the state. The price list for the medical services of these university hospitals are determined by the Ministry of Finance, which the university hospitals have to obey. In order to lower the medical expenses, the Ministry of Finance generally declares lower prices for medical services. The price list of medical drugs is also declared by the official authorities. However, drug prices are relatively very high when compared to the medical services given in the university hospitals. Therefore, the costs of specialist outpatient care and diagnostic work-up were nearly one-seventh of drug treatment cost. Social security institutions cover a great percentage of health expenses in Turkey. The reimbursement rate for hospitalisation, investigation and doctor visits is $100 \%$. For medication this is $80 \%$ for working patients and $100 \%$ for retired patients. Therefore, these high reimbursement rates increase the economic burden on society.

It has been found that headache is a considerable economic burden regarding loss of productivity [16]. In this study, the mean loss of work/school days was $1.5 \pm 5.1$ days/year/patient and the mean inefficient work/school days was $8.4 \pm 17.5$ days/year/patient. Compared to the study of Stewart et al. [17], which reported lost productive time for patients with headache as $3.5 \pm 0.1 \mathrm{~h} /$ week, our results indicated very much less loss of productivity. In a population-based diary study, migraineurs experienced an average of 3.0 lost work days/year, which was also higher than our findings [21]. Bigal et al. [22] reported the mean number of total lost working hours per month due to migraine as 6.5 in a public Brazilian hospital. These variabilities might be explained by the different designs of studies and sociocultural differences between populations. The work attendance of Turkish patients despite headache seems higher. The great difference between lost and inefficient work/school days supports this suggestion. In a study on Swedish patients the ratio of going to work despite headache among patients with headache was $50 \%[23]$
As expected, chronic TTH costs were higher than episodic headaches. The higher loss of productivity in chronic TTH had an important effect on the total cost. It was shown that indirect costs as loss of productivity at work/school days were higher for MO when compared with the episodic and chronic TTH groups, which was similar to the difference for direct cost. Mean total direct cost in the MO group was higher than in MA. However, this difference was insignificant. The differences in inefficient work/school days among groups were only statistically significant between the episodic tension-type and combined headache groups, the former causing the least and the latter causing the highest number of inefficient work/school days.

If indirect costs, calculated regarding minimum wage in Turkey (14.08 USD/day), were added to direct cost, the average total cost of migraine was found to be 242.2 USD, with a median of 160.7 USD (range: 7.6-1908.5). Many previous studies have investigated the direct and indirect costs of headache [12-15, 24]. These studies demonstrated that the indirect costs of headache were more than the direct costs. In this study, the direct cost of migraine seems higher than indirect costs, which might be explained by the low minimum wage in Turkey.

In order to overcome comparison difficulties between studies and to reach a standard value to overcome the low prices in Turkey, we calculated the average ratio of total cost of headache per patient to Gross National Product per capita for Turkey, which is 3383 USD for 2003. The average ratio was $7.2 \%$, with a median of $4.7 \%$ (range: $0.2 \%-56.5 \%$ ), which is strikingly high.

This study showed that headache, particularly migraine, might have an important economic impact on the patient and society. Therefore, in order to reduce the economic burden of migraine, proper diagnosis and treatment of migraine becomes even more important. Unfortunately, only $31 \%$ of migraineurs had sought help in their lifetime. Of those, $73 \%$ were properly diagnosed as migraine and $46 \%$ had a prescription medication [25]. Therefore, increasing awareness about migraine and proper diagnosis and treatment of migraine not only improves the patients' quality of life but helps to alleviate the economic burden as well.

As a conclusion, the results of this study, which is the first large university hospital based study investigating the direct and indirect costs of headache in Turkey, showed that headache has a considerable economic impact on headache sufferers and society. Therefore, it should be regarded as a public health problem and measures should be taken to reduce its impact on patients and society.

Acknowledgement Merck Sharpe Dohme, Turkey, provided financial support to this study 


\section{References}

1. Stewart W, Celentano D, Ziegler D, Sprecher M (1989) An epidemiologic study of headache among adolescents and young adults. JAMA 21:221-226

2. Breslau N, Rasmussen BK (2001) The impact of migraine. Epidemiology, risk factors and co-morbidities. Neurology 56[Suppl 1]:4-12

3. Zarifoğlu M, Siva A, Hayran O and the Turkish headache epidemiology study group (1998) An epidemiological study of headache in Turkey: a nationwide survey. Neurology 50[Suppl 4]:A225

4. Headache Classification Committee of the International Headache Society (2004) The international classification of headache disorders. Cephalalgia 24[Suppl 1]:1-150

5. Rasmussen BK, Jensen R, Schroll M, Olesen J (1991) Epidemiology of headache in a general population - a prevalence study. J Clin Epidemiol 44:1147-1157

6. Lipton RB, Liberman JN, Kolodner KB, Bigal ME, Dowson A, Stewart WF (2003) Migraine headache disability and health-related quality of life: a population-based case-control study from England. Cephalalgia 23:441-450

7. Korff MV, Stewart WF, Simon DJ, Lipton RB (1998) Migraine and reduced work performance. A population-based diary study. Neurology 50:1741-1745

8. Burton WN, Conti DJ, Chen CY, Schultz AB, Edington DW (2002) The economic burden of lost productivity due to migraine headache: a specific worksite analysis. J Occup Environ Med 44:523-529
9. Holmes WF, MacGregor EA, Dodick D (2001) Migraine-related disability. Impact and implications for sufferers' lives and clinical issues. Neurology 56[Suppl 1]:13-19

10. Goadsby PJ, Lipton RB, Ferrari MD (2002) Migraine: current understanding and treatment. N Engl J Med 346:257-270

11. Edmeads J, Findlay H, Tugwell P, Pryse-Phillips W, Nelson RF, Murray TJ (1993) Impact of migraine and tension-type headache on life-style, consulting behavior and medication use: a Canadian population survey. Can $\mathrm{J}$ Neurol Sci 20:131-137

12. Pradalier A, Auray JP, El Hasnaoui A, Alzahouri K, Dartigues JF, Duru G, Henry P, Lanteri-Minet M, Lucas C, Chazot G, Gaudin AF (2004) Economic impact of migraine and other episodic headaches in France: data from the GRIM2000 study. Pharmacoeconomics 22:985-999

13. Pesa J, Lage MJ (2004) The medical costs of migraine and comorbid anxiety and depression. Headache 44:562-570

14. Stang PE, Crown WH, Bizier R, Chatterton ML, White R (2004) The family impact and costs of migraine. Am J Manag Care 10:313-320

15. Lipton RB, Stewart WF, Scher AI (2001) Epidemiology and economic impact of migraine. Curr Med Res Opin 17[Suppl 1]:s4-s12

16. Burton W, Conti DJ, Chen CY, Schultz AB, Edington DW (2002) The economic burden of lost productivity due to migraine headache: a specific worksite analysis. J Occup Environ Med 44:523-529
17. Stewart WF, Ricci JA, Chee E, Morganstein D, Lipton R (2003) Lost productive time and cost due to common pain conditions in the US workforce. JAMA 290:2443-2454

18. Headache Classification Committee of the International Headache Society (1988) Classification and diagnostic criteria for headache disorders, cranial neuralgias and facial pain. Cephalalgia 8[Suppl 7]:1-96

19. Von Korff M, Ormel J, Keefe FJ, Dworkin SF (1992) Grading the severity of chronic pain. Pain 50:133-149

20. Badia X, Magaz S, Gutierrez L, Galvan $\mathrm{J}$ (2004) The burden of migraine in Spain: beyond direct costs. Pharmacoeconomics 22:591-603

21. Korff MW, Stewart WF, Simon JD, Lipton RB (1998) Migraine and reduced work performance. A population-based diary study. Neurology 50:1741-1745

22. Bigal ME, Moraes FA, Fernandes LC, Bordini CA, Speciali JG (2001) Indirect costs of migraine in a public Brazilian hospital. Headache 41:503-508

23. Raak R, Raak A (2003) Work attendance despite headache and its economic impact: a comparison between two workplaces. Headache 43:1097-1101

24. Lipton RB, Stewart WF, von Korff M (1997) Burden of migraine: societal costs and therapeutic opportunities. Neurology 48[Suppl 3]:S4-S9

25. Lipton RB, Scher AI, Kolodner K, Liberman J, Steiner TJ, Stewart WF (2002) Migraine in the United States: epidemiology and patterns of health care use. Neurology 58:885-894 